\title{
PENGARUH KAPASITOR BANK PADA BUSBAR BHA, BHB DAN BHC DI PUSAT REAKTOR SERBA GUNA GA. SIWABESSY
}

\author{
Koes Indrakoesoema, Yayan Andryanto, Kiswanto \\ Pusat Reaktor Serba Guna - BATAN \\ Kawasan Puspiptek Serpong Gedung No. 30, Kota Tangerang Selatan - Banten \\ Email : koes@batan.go.id
}

\begin{abstract}
ABSTRAK
PENGARUH KAPASITOR BANK PADA BUSBAR BHA, BHB DAN BHC DI PUSAT REAKTOR SERBA GUNA GA. SIWABESSY.Pemasangan kapasitor bank pada ke tiga jalur (BHA, BHB dan BHC) telah dilakukan, masing-masing dengan daya $500 \mathrm{kVAR}$ yang terbagi dalam 10 step, dengan tiap step $50 \mathrm{kVAR}$. Pemasangan dilakukan karena selama reaktor beroperasi total faktor daya $(\cos \varphi)$ di bawah 0,85 sehingga terkena denda oleh PLN. Pengukuran telah dilakukan saat reaktor sedang beroperasi pada bulan Juli dan September 2011 di output 3 buah transformator yang terhubung ke masing-masing busbar dengan menggunakan Power Quality Analyzer Hioki 3197. Parameter listrik yang diukur adalah daya aktif $(\mathrm{P})$, daya semu (S), daya reaktif (Q) dan faktor daya $(\cos 0)$. Kapasitor bank pada jalur BHA telah mengalami kerusakan, sehingga $\cos \varphi$ turun hingga 0,8 ; sedangkan pada jalur BHB dan BHC $\cos \varphi$ mencapai 0,92 dan 0,945 .
\end{abstract}

Kata kunci : faktor daya, kapasitor bank, transformator,

\section{ABSTRACT}

EFFECT OF CAPACITOR BANKS ON BUSBAR BHA, BHB AND BHC IN MULTT PURPOSE REACTOR GA. SIWABESSY.Instaliation of capacitor banks on the three lines (BHA, BHB and BHC) has been carried out, each with a power $500 \mathrm{kVAR}$ which is divided into 10 steps, with each step of $50 \mathrm{kVAR}$. The purpose of installation capacitor banks is during the reactor operation the total power factor (cos $\varphi$ ) below 0.85 , so incur a fine by $P L N$. Measurements have been done when the reactor is operating in July and Augusl at the output of 3 transformers which connected to each busbar using Hioki 3197 Power Quality Analyzer. electrical parameters were measured are active power $(P)$, apparent power $(S)$, reactive power $(Q)$ and power factor $(\cos \varphi)$. Capacitor banks on track $B H A$ has been damaged, so that cos $\varphi$ drops to 0.8 while cos $p$ of line $B H B$ and $B H C$ reaches 0.92 and 0.945 .

Keywords : power factor, bank capacitor, transformator

\section{PENDAHULUAY}

Salah satu cara yang paling ekonomis, mudah, dan aman untuk mengirimkan energi adalah melalui bentuk energi listrik. Energi listrik sudah menjadi kebutuhan pokok baik bagi industri maupun rumah tangga sehingga dibutuhkan kelangsungan penyaluran sistem tenaga listrik secara handal dan baik.

Penggunaan yang efisien dan pemasangan peralatan listrik serta komponen yang tepat akan membantu dalam penggunaan encrgi listrik secara hemat dan mempunyai manfaat optimal seperti yang diharapkan.

Penerapan program penghematan energi di kantor-kantor pemerintah dapat memperkecil biaya energi untuk setiap satuan produk (specific energy consumption) disamping akan menghemat pemakaian energi nasional, juga akan menghemat pemakaian anggaran.

Pusat Reaklor Serba Guna (PRSG) BATAN terdiri dari 2 gedung, yaitu Gedung No.30 yang merupakan gedung reaktor beserta fasilitas laboratorium dan Gedung No.31 yang merupakan gedung perkantoran, di mana energi listrik untuk ke dua gedung tersebut di catu oleh PLN melalui 3 buah transformator 20 $\mathrm{kV} / 400 \mathrm{~V}$ ke masing-masing bushar BHA, BHB dan BHC.

Masing-masing busbarmencatu berbagai 
tipe beban, antara lain motor pompa, motor katub, motor chiller, penerangan, lift, dan lain sebagainya. Kontrak daya dengan PLN telah mengalami 2 (dua) kali perubahan, kontrak daya pertama adalah $4805 \mathrm{kVA}$ kemudian dilakukan penurunan daya menjadi $3805 \mathrm{kVA}$, dan terakhir diturunkan kembali menjadi 3030 kVA. Hal ini dilakukan karena daya yang digunakan di reaktor selama ini, rata-rata adalah $1834 \mathrm{kV} \Lambda$ atau sekitar $60,5 \%$.

Pemasangan kapasitor bank telah dilakukan pada tiap-tiap busbar, yaitu masingmasing $500 \mathrm{kVA}$ dengan tujuan memperbaiki faktor daya agar lebih besar dari 0,85 sehingga tidak terkena denda oleh PLN. Pada makalah ini akan dianalisis pengaruh kapasitor bank pada ke tiga jalur, serta kegagalan 1 set kapasitor bank pada satu jalur, yaitu jalur BHA.

\section{TEORI}

Sistem distribusi dikenal dengan sistem distribusi primer yaitu tegangan dari tegangan tinggi (TT) diturunkan ke tegangan menengah (TM) dengan menggunakan step down transformer, dan sistem distribusi sekunder dimana tegangan TM diturunkan lagi ke tegangan rendah (TR).

Pemakaian listrik yang menggunakan tegangan rendah diperoleh dengan cara menurunkan tegangan menengah $20 \mathrm{kV}, 12 \mathrm{kV}$ atau $6 \mathrm{kV}$ ke tegangan $380 \mathrm{~V} / 220 \mathrm{~V}$ dengan transformator penurun tegangan pada gardu tiang ataupun gardu beton yang berada dilingkungan sekitar konsumen.

Penghematan pemakaian energi listrik (kWh) oleh konsumen dapat dilakukan dengan lima cara, yaitu : ${ }^{[1]}$

1. Menggunakan beban listrik yang hemat energi,

2. Meminimalkan waktu pemakaian energi listrik,

3. Meminimalkan rugi jaringan dengan menggunakan penghantar berpenampang besar dan atau menggunakan tegangan tinggi,

4. Mengurangi rugi konduktor dengan menggunakan material superconductor,

5. Meminimalkan rugi jaringan dengan mengkompensir daya reaktif induktif/kapasitif.

\section{Beban-Beban Listrik ${ }^{[2]}$}

Jenis-jenis beban listrik terbagi atas 3 jenis beban yaitu :

a). Bebanresistif

b). Bebaninduktif

c). Bebankapasitif

\section{Beban resistif (resistor)}

Beban resistif (resistor): adalah beban yang berasal dari suatu komponen tahanan murni dengan simbol (R), memiliki satuan ohm $(\Omega)$. Beban resistif terdapat pada generator, bahan penghantar saluran, transformator, motor listrik, pemanas listrik (heater), dan lain sebagainya.

Bila dihubungkan pada sumber arus bolak-balik (Gambar 1), maka beban resistif memiliki karakteristik sebagaimana pada Gambar 2.

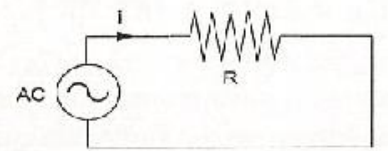

\section{Gambar 1. Beban resistif pada sumber arus bolak-balik}

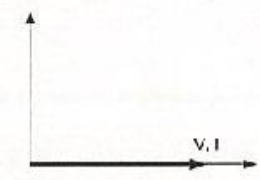

\section{Gambar 2. Diagram vektor beban resistif}

Resistansi suatu beban diberikan oleh persamaan (1):

$$
R=\frac{V(t)}{i(l)}
$$

dengan $V(t)$ menyatakan besar tegangan listrik sebagai fungsi waktu, dan $i(t)=$ besar arus yang mengalir fungsi waktu.

\section{Beban induktif (induktor)}

Beban induktif (induktor) adalah beban yang berasal dari suatu penghantar untuk menghasilkan medan magnet yang dipergunakan untuk mengubah energi mekanik menjadi energi listrik ataupun sebaliknya, menaikkan atau menurunkan tegangan listrik, dan lain sebagainya. Induktor itu sendiri memiliki simbol (L) dengan satuan Ilenry (Gambar 3). Beban induktif terdapat pada suatu saluran transmisi yang merupakan rugi-rugi dari saluran tersebut. Beban induktif juga terdapat pada generator, motor listrik, kontaktor 
magnet, dan lain sebagainya.

Induktansi diberikan dengan persamaan (2) dan (3)

$$
\begin{aligned}
& V(t)=\mathrm{L} \frac{d i}{d t} \operatorname{dan} i(\mathrm{t})=\frac{1}{\mathrm{~L}} \int V \mathrm{~d} t \\
& \mathrm{~L}=\frac{V(t)}{\mathrm{d} i / \mathrm{d} t}
\end{aligned}
$$

dengan $V(\mathrm{t})$ menyatakan besar tegangan listrik dalam fungsi waktu, dan $\mathrm{d} i / \mathrm{d} t$ adalah turunan pertama dari arus terhadap waktu.

Bila induktor dihubungkan pada sumber arus bolak-balik (Gambar 3) maka beban induktif memiliki karakteristik sebagaimana ditunjukkan pada Gambar4.

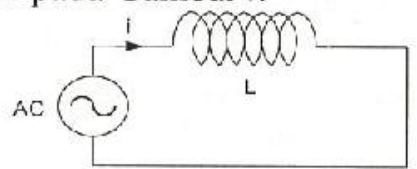

\section{Gambar 3. Beban induktif pada sumber arus bolak-balik}

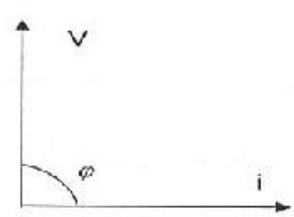

\section{Gambar 4. Diagram vektor beban induktif}

Reaktansi induktif suatu beban diberikan oleh persamaan (4)-(5).

$$
X_{\mathrm{L}}=\omega \mathrm{L}=\frac{V}{I}
$$

maka,

$$
\mathrm{L}=\frac{V}{I \omega}
$$

dengan $\omega$ menyatakan keccpatan sudut $[\mathrm{rad} / \mathrm{sec}]=2 \pi f$; dan $f$ adalah frekuensi tegangan.[Hertz], serta $X_{\mathrm{L}}$ reaktansi induktif $[\Omega]$

\section{Beban kapasitif (kapasitor)}

Beban kapasitif (kapasitor) adalah beban yang berasal dari dua bahan penghantar (konduktor) yang terpisah, dengan polaritas yang berbeda pada penghantarnya. Beban kapasitif ini berfungsi menyimpan muatan listrik. Beban kapasitif diantaranya terdapat pada: saluran penghantar, mesin sinkron berpenguatan lebih, kapasitor, dan lain sebagainya. Kapasitor memiliki simbol (C) dengan satuan Farad.

Kapasitansi diberikan dengan persamaan (6)(9).

$$
\begin{aligned}
& V(t)=\frac{1}{\mathrm{C}} \int i \mathrm{~d} t \\
& i(t)=\frac{\mathrm{d} Q}{\mathrm{~d} t}=\mathrm{C} \frac{\mathrm{d} V}{\mathrm{~d} t} \\
& Q(t)=\mathrm{C} V(t) \\
& \text { maka: } \\
& \mathrm{C}=\frac{Q}{V}=\frac{\varepsilon \cdot A}{d^{\prime}}=\frac{\varepsilon_{0} \varepsilon_{\mathrm{r}} A}{d}
\end{aligned}
$$

dengan $V(t)$ menyatakan besar tegangan listrik dalam fungsi waktu(volt), di/d $/$ adalah turunan pertama dari arus terhadap waktu (ampere], Cbesar kapasitansi (farad), Qmuatan pada salah satu konduktor (coulomb), Vtegangan kedua konduktor (volt), epermitivitas bahan antara dua penghantar, $\varepsilon_{0}$ permitivitas udara $\left(4 \pi .10^{-7}\right)$, $\varepsilon_{\varepsilon}$ permitivitas relatif bahan, dan Aluas masingmasing plat penghantar, serta djarak antara dua penghantar.

Bila kapasitor dihubungkan pada sumber arus bolak-balik (Gambar 5), maka beban kapasitif memiliki karakteristik sebagai mana dibcrikan pada Gambar 6.

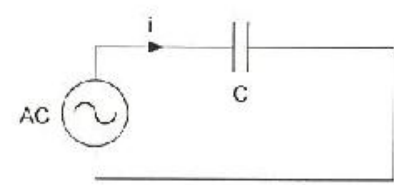

Gambar 5. Beban kapasitif pada sumber arus bolak-balik

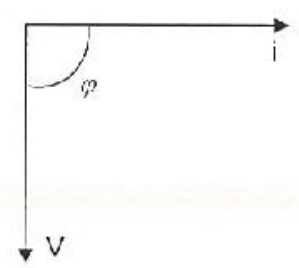

\section{Gambar 6. Diagram vektor beban kapasitif} dielektrik udara

\section{Daya listrik ${ }^{[2]}$}

Daya listrik adalah banyaknya perubahan tenaga listrik terhadap waktu dalam besaran tegangan dan arus dengan satuan watt. Daya dalam satuan watt yang diserap olch suatu beban pada setiap saat adalah hasil kali 
tegangan beban sesaat (volt) dengan arus sesaat yang mengalir dalam beban tersebut (ampere).

Dalam kelistrikan dikenal adanya beberapa jenis daya, yaitu :
a) Daya semu $(S)$
b) Daya aktif (P)
c) Daya reaktif $(Q)$

\section{Daya semu}

Daya semu untuk sistem fasa tunggal dengan sirkuit dua kawat adalah perkalian skalar arus dan tegangan efektifnya. Daya semu $(S)$ dinyatakan melalui persamaan (10).

$$
S=|V||I|
$$

Sedangkan untuk sistem 3 fasa daya semu dinyatakan oleh persamaan (11).

$$
S=3|V||I|
$$

\section{Daya aktif} (12).

Daya aktif dinyatakan oleh persamaan

$$
P=\frac{V_{\text {mks }} I_{\text {maks }}}{2} \cos \varphi
$$

dengan $P$ menyatakan daya rata-rata yang juga disebut sebagai daya aktif.

Persamaan untuk daya beban tiga fasa yang seimbang dinyatakan oleh persamaan (13).

$$
P=\sqrt{3} V_{\text {jala-jala }}\left|f_{\text {:ala-jiala }}\right| \cos \varphi \text { (watt) }
$$

dengan $V_{\text {jalk:jila }}$ menyatakan tegangan efektif, dan $\mathrm{I}_{\text {jala-jala }}$ adalah arus jala efektif.

\section{Daya reaktif}

Daya reaktif dituliskan dengan persamaan (14).

$$
\begin{aligned}
& Q=\frac{V_{\text {maks }} I_{\text {maks }}}{2} \sin \varphi \\
& Q=|V||| \mid \sin \varphi \quad[\mathrm{VAr}]
\end{aligned}
$$

\section{Segitiga daya ${ }^{[1]}$}

Hubungan antara daya semu (S), daya aktif $(P)$ dan daya reaktif ( $Q$ ) dikenal dengan istilah segitiga daya. Irubungan antara ketiganya, baik untuk beban bersifat induktif maupun untuk beban bersifat kapasitif dapat dilihat pada Gambar 7 .

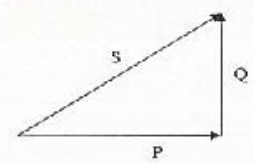

\section{Gambar 7. Segitiga daya}

dengan $\mathrm{P}=$ V.I. $\cos \varphi$, dan $\mathrm{S}=\mathrm{V} . \mathrm{I}$, serta $\mathrm{Q}=$ V.I. $\sin 0$

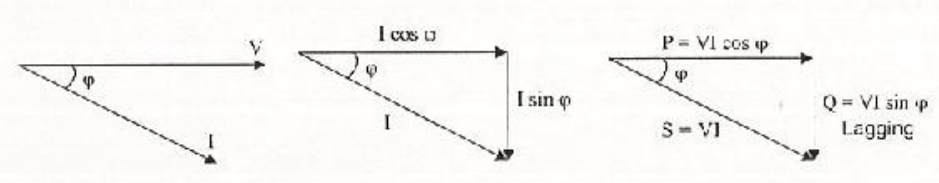

Gambar 8. Segitiga daya untuk beban induktif
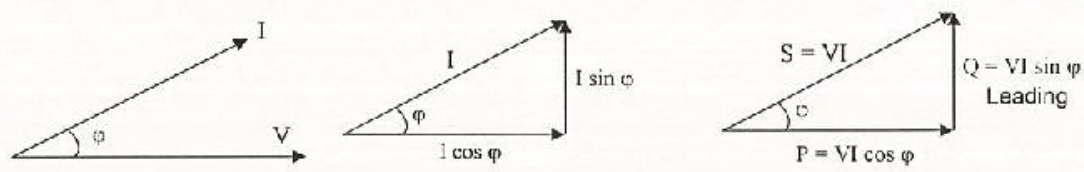

Gambar 9.Segitiga daya untuk beban kapasitif

Dari Gambar 8 dan Gambar 9 diperoleh persamaan (16).

$S=\sqrt{P^{2}+Q^{2}}$ atau $P=S \cos Q=S \sin \varphi$

\section{Faktor daya ${ }^{[1]}$}

Faktor daya pada dasarnya didefinisikan sebagai perbandingan daya reaktif dengan daya semu dan dapat dirumuskan dengan persamaan
(17).

$$
\text { Faktorday } \mathrm{a}=\cos \varphi=\frac{P(\text { day aaktif })}{S(\text { day asemu })}
$$

Sudut $\phi$ adalah sudut fasa; dimana arus mendahului tegangan (leading) atau arus tertinggal dari tegangan (lagging) dari beban yang bersangkutan. Semua peralatan listrik, kecuali motor sinkron, tahanan-pemanas dan 
lampu pijar, mengkonsumsi daya listrik pada faktor kerja pengikut (lagging).

\section{Beban Pada Jalur BHA, BHB dan BHC}

Gedung reaktor GA Siwabessy dicatu oleh 3 buah transformator (BHTO1, BHTO2 dan $\mathrm{BHT} 03$ ), masing-masing mempunyai kapasitas
$1600 \mathrm{kVA}, 20 \mathrm{kV} / 400 \mathrm{~V}$. Tiga buah transformator ini masing-masing dihubungkan ke 3 buah busbur BHA, BHB dan BHC, seperti terlihat pada Gambar 10.

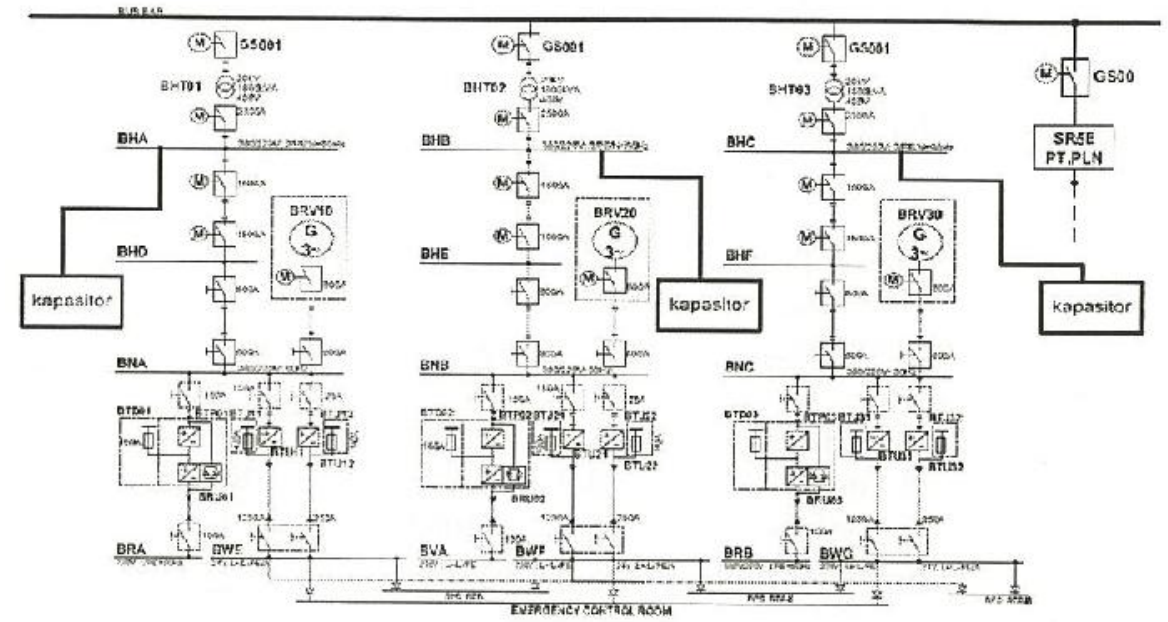

Gambar 10. Diagram segaris sistem listrik RSG-GAS

Tabel 1,2 dan 3 menunjukkan jenis beban BHB dan BHC. dan dayanya yang melalui tiap-tiap jalur BHA,

Tabel 1. Beban pada jalur BHA ${ }^{3)}$

\begin{tabular}{|c|c|c|c|c|}
\hline \multicolumn{5}{|l|}{ BHA 01 } \\
\hline No. & Jenis Beban & Kode & Daya $(\mathbf{k W})$ & Rated (A) \\
\hline 1. & Motor Katup & PA-01 AA001 & 1,1 & 3,2 \\
\hline 2. & Motor Katup & PA-01 AA003 & 0,55 & 1,9 \\
\hline 3. & Motor Katup & PA-01 AA010 & 0,55 & 1,9 \\
\hline 4. & Motor Katup & PA-01 AA011 & 0,03 & 0,5 \\
\hline 5. & Motor Katup & PA-01 AA012 & 0,55 & 1,9 \\
\hline 6. & Motor Katup & PA-01 AA014 & 0,55 & 1,9 \\
\hline 7. & Motor Katup & PA-01 AA016 & 0,55 & 1,9 \\
\hline 8. & Motor Katup & PA-01 AA020 & 0,55 & 1,9 \\
\hline 9. & Motor Katup & PA-01 AA022 & 0,55 & 1,9 \\
\hline \multicolumn{5}{|l|}{ BHA 02 } \\
\hline 10. & Motor Fan & PA-01 AII001 & 30 & 70 \\
\hline 11. & Motor Fan & PA-01 AH002 & 30 & 70 \\
\hline 12. & Motor Fan & PA-01 AH003 & 30 & 70 \\
\hline \multicolumn{5}{|l|}{ BHA 05} \\
\hline 13. & Motor Pompa & PA-01 AP001 & 220 & 414 \\
\hline \multicolumn{5}{|l|}{ BHA 06} \\
\hline 14 & Hydraulic Booster & GHC02 GS001 & 5 & $125 / 10^{8 \times}$ \\
\hline 15. & Chilled Water Plant & QKJ00 GS001 & 135 & $400^{*} / 300^{* *}$ \\
\hline & TOTAL & & 474,98 & \\
\hline
\end{tabular}


Tabel 2. Beban pada jalur $\mathrm{BHB}^{3)}$

\begin{tabular}{|c|c|c|c|c|}
\hline \multicolumn{5}{|c|}{ ВНB 01} \\
\hline No. & Jenis Beban & Kode & Daya $(k W)$ & Rated (A) \\
\hline 1. & Motor Katup & PA-02 AA001 & 1,1 & 4 \\
\hline 2. & Motor Katup & PA-02 AA003 & 1,1 & 4 \\
\hline 3. & Motor Katup & $\mathrm{PA}-02 \mathrm{AA} 010$ & 0,55 & 1.6 \\
\hline 4. & Motor Katup & PA-02 AA011 & 0,03 & 1 \\
\hline 5. & Motor Katup & P^-02 AА012 & 0,55 & 1,6 \\
\hline 6. & Motor Katup & PA-02 AA014 & 0,55 & 1,6 \\
\hline 7. & Motor Katup & PA-02 AA016 & 0,55 & 1,6 \\
\hline 8. & Motor Katup & $\mathrm{PA}-02 \mathrm{AA} 020$ & 0,55 & 1.6 \\
\hline 9. & Motor Katup & $\mathrm{PA}-02 \mathrm{AA} 022$ & 0,37 & 1,6 \\
\hline 10. & Motor Katup & PA-02 AA004 & 0,03 & 1 \\
\hline \multicolumn{5}{|c|}{ BHB 02} \\
\hline 11. & Motor Pompa & PA-04 AP002 & 4,4 & 16 \\
\hline 12. & Motor Fan & $\mathrm{PA}-02 \mathrm{AHOOL}$ & 30 & $80^{*} / 125^{* *}$ \\
\hline 13. & Motor Fan & $\mathrm{PA}-02 \mathrm{AHOO} 2$ & 30 & $80^{*} / 125^{* *}$ \\
\hline 14. & Motor Fan & $\mathrm{PA}-02 \mathrm{AH} 003$ & 30 & $80^{*} / 125^{* *}$ \\
\hline \multicolumn{5}{|c|}{ BHB 05} \\
\hline 15. & Motor Pompa & PA-02 AP001 & 220 & $315^{*} / 400^{* *}$ \\
\hline \multicolumn{5}{|c|}{ BHB 06} \\
\hline 16. & Panel & GCA01 GS001 & 25 & $50 \% / 125^{* \pi}$ \\
\hline 17. & Motor Crane & SMK00 & 7 & $16^{*} / 125^{* *}$ \\
\hline 18. & $\begin{array}{l}\text { Panel Motor } \\
\text { Ventilasi }\end{array}$ & QKJ00 GS002 & 135 & $300^{*} / 400^{* *}$ \\
\hline & TOTA & & 486,78 & \\
\hline
\end{tabular}

Tabel 3. Beban Parla Jalur BHC

\begin{tabular}{|c|c|c|c|c|}
\hline \multicolumn{5}{|l|}{ BHC 01} \\
\hline No. & Jenis Beban & Kode & Daya $(k W)$ & Rated (A) \\
\hline 1. & Motor Katup & PA-03 AA004 & 0,55 & 1,6 \\
\hline 2. & Motor Katup & PA-03 AA003 & 0,06 & 1 \\
\hline 3. & Motor Katup & PA-05 A $\triangle 002$ & 0,06 & 1 \\
\hline 4. & Motor Katup & PA-03 AA011 & 0,55 & 1,6 \\
\hline 5. & Motor Katup & PA-03 AA012 & 0,55 & 1,6 \\
\hline 6. & Motor Katup & PA-03 AA 013 & 0,55 & 1,6 \\
\hline 7. & Motor Katup & PA-04 AA002 & 0,03 & 1 \\
\hline 8. & Motor Katup & PD-01 AA001 & 0,55 & 1,6 \\
\hline 9. & Motor Katup & PD-01 $\triangle \wedge 002$ & 0,55 & 1,6 \\
\hline \multicolumn{5}{|c|}{ BHC 02} \\
\hline 10. & Motor Katup & PD-01 AA003 & 0,55 & 1,6 \\
\hline 11. & Motor Katup & GBA01 AA001 & 0,06 & 1 \\
\hline 12. & Motor Fan & PD-01 AH001 & 30 & $80^{*} / 125^{* *}$ \\
\hline 13. & Motor Pompa & PA-04 AP001 & 4,4 & 16 \\
\hline \multicolumn{5}{|c|}{ BHC 05} \\
\hline 14 & Motor Pompa & PA-05AP001 & 2,5 & 6.3 \\
\hline 15. & Motor Pompa & PA-03 AP001 & 220 & $315^{\prime \prime} / 400^{\circ \prime \prime}$ \\
\hline
\end{tabular}


Tabel 3. Lanjutan

\begin{tabular}{|c|c|c|c|c|}
\hline BHC 06 & & & & \\
\hline 16. & Panel & UKA04 GP101 & 33 & 63 \\
\hline 17. & Panel & $\begin{array}{c}\text { PAH01/02 } \\
\text { GS001 }\end{array}$ & 5 & 10 \\
\hline 18. & $\begin{array}{l}\text { Panel Motor } \\
\text { Ventilasi }\end{array}$ & KLCO0 GS001 & 26 & 50 \\
\hline 19. & $\begin{array}{c}\text { Panel Motor } \\
\text { Ventilasi }\end{array}$ & QKJ00 GS003 & 135 & $300^{*} / 400^{* *}$ \\
\hline & TOTAL & & 459,96 & \\
\hline
\end{tabular}

\section{METODE}

Pengukuran parameter listrik dilakukan pada saat reaktor operasi, dimana beban-beban pada jalur BHA, BHB dan BHC pada keadaan maksimal. Peralatan yang digunakan adalah Power Quality Analizer Hioki 3197 dan dipasang pada output transformator BHT01, BHT02 dan BHT03. Lihat Gambar 10. Pengukuran pada jalur BHA dilakukan pada bulan September 2011 selama 24 jam, pada jalur BHB dan BHC pada bulan Agustus 2011 selama 24 jam.

\section{HASIL DAN PEMBAHASAN}

Panel pada busbar BHA, BHB dan BHC telah dipasang kapasitor bank dengan daya masing-masing $500 \mathrm{kVAR}$. Hasil pengukuran daya dan faktor daya $(\cos \varphi)$ pada busbar $\mathrm{BHA}$ dapat dilihat pada Gambar 11 dan Gambar 12.

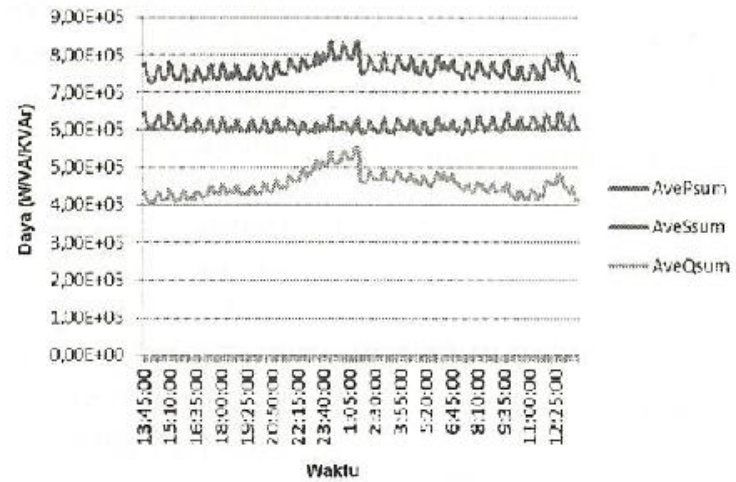

Gambar 11. Daya (P, S, dan Q) pada jalur BHA

Dari Gambar 11 terlihat rata-rata daya aktif (P) adalah $610 \mathrm{~kW}$, daya semu (S) adalah 762 kVA dan daya reaktif (Q) adalah 455 kVAR. Tingginya daya reaktif discbabkan kegagalan kapasitor bank dalam memperbaiki faktor daya, hal ini bisa dilihat pada Gambar 12 , dimana $\cos 0$ jatuh pada harga 0,8 dan sempat terjadi fluktuasi beban sesaat dimana $\cos \varphi$ turun hingga 0,74 .

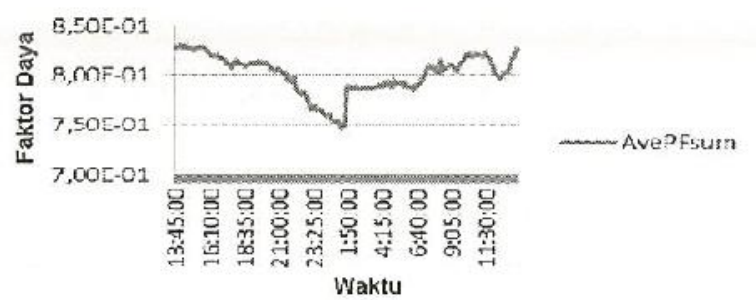

Gambar 12. Faktor daya $(\cos \varphi)$ beban jalur BHA

Daya dan faktor daya pada jalur BHB dapat dilihat pada Gambar 13 dan Gambar 14. 


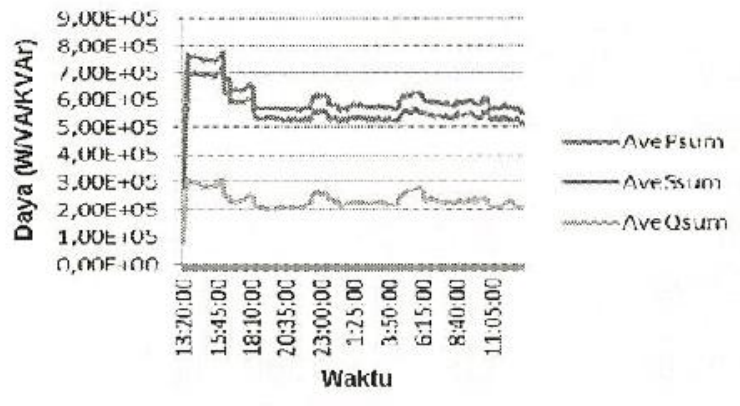

Gambar 13. Daya (P, S, dan Q) pada jalur BHB

Dari Gambar 13 terlihat daya aktif jauh lebih besar dari daya reaktif, dimana $\mathrm{P}=558$ $\mathrm{kW}$, daya semu, $\mathrm{S}=605 \mathrm{kVA}$ dan daya reaktif; $\mathrm{Q}=235 \mathrm{kVAR}$. Hal ini menunjukkan kapasitor bank masih berfungsi baik dimana faktor daya lebih besar dari 0,85 , seperti terlihat pada Gambar 14, yaitu 0,92.

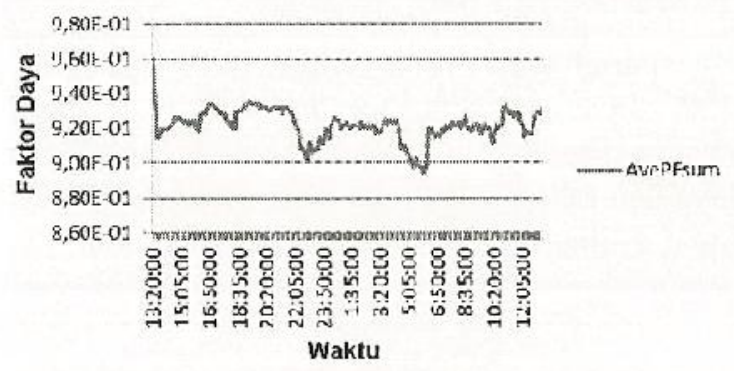

\section{Gambar 14. Faktor daya $(\cos \varphi)$ beban jalur BHB}

Pada jalur BHC, daya aktif, daya semu dan daya reaktif dapat dilihat pada Gambar 15 dan faktor dayanya pada Gambar 16.

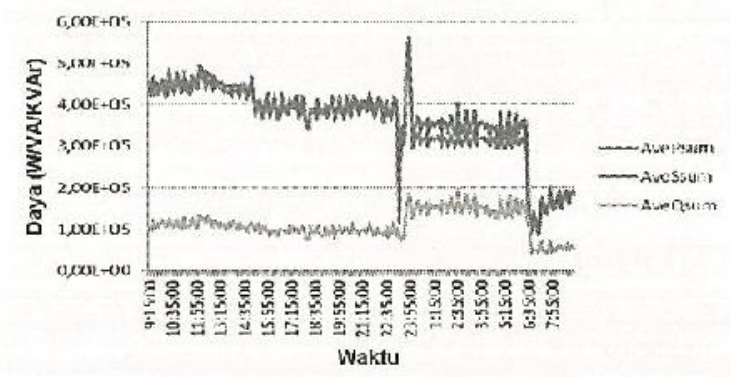

Gambar 15. Daya (P, S, dan Q) pada jalur BHC

Pada Gambar 15 terlihat daya aktif $P$ lebih besar dari daya reaktif $Q$, saat terjadi fluktuasi beban daya aktif $300 \mathrm{~kW}$ diikuti kenaikan daya reaktif menjadi $150 \mathrm{kVAR}$. Rata-rata daya aktif $P=351 \mathrm{~kW}$, daya semu $\mathrm{S}$ $=369 \mathrm{kVA}$ dan daya reaktif $\mathrm{Q}=110 \mathrm{kVAR}$.

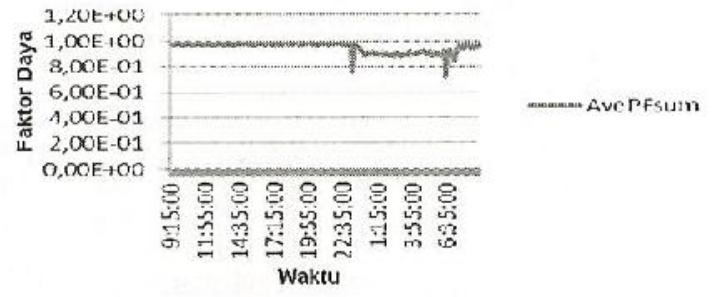

\section{Gambar 16. Faktor daya $(\cos \varphi)$ beban jalur BHC}

Faktor daya pada jalur BHC saat pengukuran sempat mengalami penurunan sampai di bawah 0,85 dalam waktu singkat, hal ini dikarenakan adanya fluktuasi beban, namun rata-rata cos o selama 24 jam adalah 0,945 , dengan demikian kapasitor bank pada jalur BIIC masih berfungsi baik.

\section{KESIMPULAN}

Kapasitor bank pada jalur BHA mengalami kerusakan sehingga faktor daya turun hingga 0,8 sedangkan pada jalur BHB dan BHC faktor daya masih berfungsi baik karena masih di atas 0,85 , yaitu masing-masing 0,92 dan 0,945 .

\section{DAFTAR PUSTAKA}

1. Zuhal, Dasar Teknik Tenaga Listrik dan Elektronika Daya, Gramedia Pustaka Utama, Jakarta, (1995).

2. Pabla, A.S, Hadi, A., Sistem Distribusi Daya Listrik, Erlangga, Jakarta, (1986).

3. Indrakoesoema, K., Optimasi Pemakaian Energy Listrik Pada Gedung 90 PKTN BATAN, Prosiding PPI-PDIPTN 2008, Yogyakarta, 15 Juli 2008.

4. INTERATOM, Maintenance and Repair Manual (MRM) MPR30, (1988). 